\title{
Relationship Between ACE2 and Other Components of the Renin-Angiotensin System
}

\author{
Jordana B. Cohen ${ }^{1,2} \cdot$ Thomas C. Hanff ${ }^{2,3}$ • Adam P. Bress ${ }^{4} \cdot$ Andrew M. South ${ }^{5,6,7}$ \\ Published online: 26 June 2020 \\ (C) Springer Science+Business Media, LLC, part of Springer Nature 2020
}

\begin{abstract}
Purpose of the Review Angiotensin-converting enzyme 2 (ACE2) is a key counter-regulatory component of the reninangiotensin system. Here, we briefly review the mechanistic and target organ effects related to ACE2 activity, and the importance of ACE2 in SARS-CoV-2 infection.

Recent Findings ACE2 converts angiotensin (Ang) II to Ang-(1-7), which directly opposes the vasoconstrictive, proinflammatory, and prothrombotic effects of Ang II. ACE2 also facilitates SARS-CoV-2 viral entry into host cells. Drugs that interact with the renin-angiotensin system may impact ACE2 expression and COVID-19 pathogenesis; however, the magnitude and direction of these effects are unknown at this time.

Summary High quality research is needed to improve our understanding of how agents that act on the renin-angiotensin system impact ACE2 and COVID-19-related disease outcomes.
\end{abstract}

Keywords COVID-19 • Angiotensin-converting enzyme - Renin-angiotensin system · Angiotensin receptor blockers . Angiotensin-converting enzyme inhibitors $\cdot$ Hypertension $\cdot$ Coronavirus infections $\cdot$ Chronic kidney disease $\cdot$ Cardiovascular disease

\section{Introduction}

The severe acute respiratory syndrome coronavirus 2 (SARSCoV-2), the virus responsible for the coronavirus disease 2019 (COVID-19) pandemic, is associated with a high risk of acute respiratory distress syndrome and mortality [1-4]. Angiotensin-converting enzyme 2 (ACE2) facilitates SARS$\mathrm{CoV}-2$ entry into host cells in the respiratory tract, and altered

Jordana B. Cohen

jco@pennmedicine.upenn.edu

1 Renal-Electrolyte and Hypertension Division, Department of Medicine, Perelman School of Medicine, University of Pennsylvania, Philadelphia, PA, USA

2 Department of Biostatistics, Epidemiology, and Informatics, Perelman School of Medicine, University of Pennsylvania, Philadelphia, PA, USA

3 Division of Cardiology, Department of Medicine, Perelman School of Medicine, University of Pennsylvania, Philadelphia, PA, USA
ACE2 regulation is speculated to play a role in the pathogenesis of COVID-19 [5]. In the setting of the COVID-19 pandemic, there has been increasing interest in the physiologic and pathophysiologic function of ACE2 [6•]. Here, we briefly review the role of ACE2 in the renin-angiotensin system, the therapeutic potential of ACE2, and potential interactions of ACE2 with SARS-CoV-2 and its role in COVID-19 pathophysiology.

4 Division of Health System Innovation and Research, Department of Population Health Sciences, University of Utah, Salt Lake City, UT, USA

5 Section of Nephrology, Department of Pediatrics, Wake Forest School of Medicine and Brenner Children's Hospital, Winston Salem, USA

6 Department of Epidemiology and Prevention, Division of Public Health Sciences, Wake Forest School of Medicine, Winston Salem, USA

7 Department of Surgery-Hypertension and Vascular Research, Wake Forest School of Medicine, Winston Salem, NC, USA 


\section{Counter-Regulatory Effects of ACE2 in the Renin-Angiotensin System}

ACE2 is a mono-carboxypeptidase with a single enzymatic binding site that acts as a key counter-regulatory component of the renin-angiotensin system [7]. ACE2 is the only known homolog of ACE; it shares $42 \%$ of sequence identity with somatic ACE and $61 \%$ similarity in the area surrounding the active site $[8,9]$. ACE2 is expressed on the surface of endothelial and epithelial cells in membranebound form as well as soluble form in several tissues throughout the body, including the kidneys, heart, gastrointestinal tract, and lungs [10, 11].

ACE converts angiotensin I (Ang I) to Ang II, which acts on the Ang II type 1 receptor $\left(\mathrm{AT}_{1} \mathrm{R}\right)$, resulting in vasoconstriction, sodium and fluid retention by the kidney, oxidative stress, inflammation, fibrosis, and impaired fibrinolysis $[11,12]$. In direct opposition to the cascade of physiological effects of the ACE/Ang II pathway, the net effect of the ACE2/Ang-(1-7) pathway is vasodilation and anti-inflammation. ACE2 hydrolyzes Ang II, converting it to Ang-(1-7) (see Fig. 1). The conversion of Ang II to Ang-(1-7) diminishes the availability of Ang II to bind $\mathrm{AT}_{1} \mathrm{R}$, forestalling the vasoconstrictive, proinflammatory, and prothrombotic effects of $\mathrm{AT}_{1} \mathrm{R}$ activation [7, 10-13]. Additionally, Ang-(1-7) acts on the Mas receptor, causing the release of nitric oxide, prostaglandin $\mathrm{E}_{2}$, and bradykinin [11] resulting in vasodilation, natriuresis, and a reduction in oxidative stress and inflammation $[14,15]$. ACE2 also cleaves several other peptides, including converting Ang I to Ang-(1-9), which is a lessbioactive peptide [16]

\section{Systemic Effects of ACE2}

ACE2 plays an important role in the development of several pathologic conditions, including hypertension, cardiac hypertrophy, and kidney disease. For example, in human kidney tissue, the ratio of ACE to ACE2 expression is higher in subjects with hypertension compared with those without hypertension [17]. These findings are consistent with morepronounced vasoconstrictive and anti-natriuretic effects of ACE, compared with ACE2, activity in hypertensive individuals. Several experimental and human studies have also demonstrated a reduction in glomerular ACE2 expression in diabetic and non-diabetic kidney disease [8]. Correspondingly, experimental studies in mice show that pharmacologic inhibition of ACE2 promotes the development of microalbuminuria and diabetic nephropathy $[18,19]$. Human data suggest that ACE2 may be upregulated in individuals with existing cardiovascular disease, which is speculated to be a compensatory response to counteract the deleterious effects of Ang II [20]. In SARS-CoV-2, while ACE2 facilitates viral entry in host cells, it may also have protective effects against severe acute lung injury [21].

\section{ACE2 as a Therapeutic Target}

Given its vasodilatory, natriuretic, anti-inflammatory, and anti-fibrotic effects via increased Ang-(1-7) and decreased Ang II, soluble ACE2 has been proposed as a potential therapeutic target in hypertension, chronic kidney disease, cardiovascular disease, and viral respiratory disease. In experimental studies, chronic administration of soluble ACE2 has been

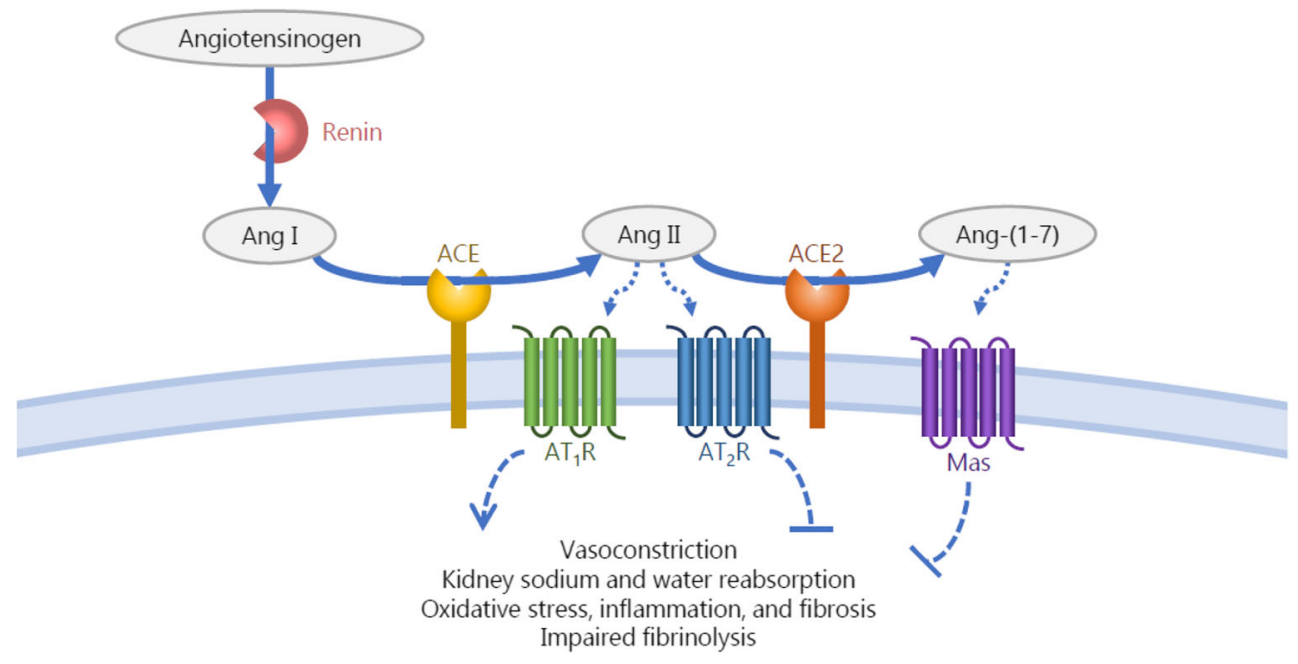

Fig. 1 The counter-regulatory role of ACE2 in the renin-angiotensin system. This figure demonstrates the conversion of angiotensinogen to Ang I by renin, Ang I to Ang II by ACE, and Ang II to Ang-(1-7) by $\mathrm{ACE} 2$. Ang II acts on the $\mathrm{AT}_{1} \mathrm{R}$ receptor to increase vasoconstriction, fluid and sodium retention by the kidney, and oxidative stress, resulting in increased blood pressure. Ang-(1-7) acts on the Mas receptor resulting in vasodilation, increased fluid and sodium excretion by the kidney, and a reduction in oxidative stress, resulting in reduced blood pressure 
associated with degradation of Ang II and an increase in Ang-(1-7) [22-24]. Animal studies consistently demonstrate a reduction in blood pressure with recombinant $\mathrm{ACE} 2$ administration, and in mouse models, recombinant ACE2 attenuated diabetic kidney injury [22] and myocardial remodeling [24]. Recombinant ACE2 has also been proposed as a treatment for severe viral pneumonia and acute respiratory distress syndrome. Recombinant ACE2 reduces acute lung injury and acute respiratory distress syndrome in mice with viral pneumonia [25]. Children infected with respiratory syncytial virus have higher plasma Ang II concentration compared with healthy controls, suggesting upregulation of ACE/Ang II and downregulation of ACE2/Ang-(1-7), and supporting ACE2 as a potential therapy in respiratory syncytial viral lung disease in humans.

ACE inhibitors block the conversion of Ang I to Ang II, while Ang II receptor blockers directly inhibit $\mathrm{AT}_{1} \mathrm{R}$. Both of these medications decrease blood pressure and inflammation and mitigate fibrosis in hypertension, cardiovascular disease, and chronic kidney disease. In several animal models, these antihypertensive agents have been shown to increase ACE2 expression in the heart and kidneys [26-29]. However, in humans, ACE inhibitors and Ang II receptor blockers have not been associated with increased kidney ACE2 expression or circulating ACE2 activity [30, 31•].

\section{The Relationship Between ACE2 and COVID-19}

ACE2 is the binding site for the SARS-CoV-2 viral spike (S) protein and facilitates viral entry into the host cell. There has been recent speculation that ACE inhibitors and Ang II receptor blockers may increase the risk of development and severity of COVID-19 due to potential upregulation of ACE2 by these medications [32]. However, SARS-CoV-2 facilitates ACE2 endocytosis, downregulates ACE2 expression, and promotes ACE2 shedding from the cell surface, leading to an increase in Ang II concentration and a decrease in Ang-(1-7). This is likely important in COVID-19 pathophysiology due to the proinflammatory effects of Ang II with corresponding loss of Ang-(1-7)-mediated counter-regulation [33]. The prothrombotic effects of excess Ang II could underlie COVID-19 hypercoagulability [34, 35•]. Upregulation of ACE/Ang II with downregulation of ACE2/Ang-(1-7) in the vascular endothelium could promote COVID-19-associated vasculopathy [36, 37]. Extrapolating from SARS-CoV animal models, increased Ang II in patients with COVID-19 due to loss of ACE2 could mediate acute lung injury and acute respiratory distress syndrome [38]. In experimental models, Ang II administration induces $\mathrm{AT}_{1} \mathrm{R}$-mediated ACE2 internalization and degradation [39]. ACE inhibitors and Ang II receptor blockers may have a therapeutic benefit in COVID-19 by reducing Ang II concentration and $\mathrm{AT}_{1} \mathrm{R}$ activation. Thus, it remains unclear if ACE inhibitors or Ang II receptor blockers have a beneficial or harmful effect in SARS-CoV-2 infection and COVID-19.

\section{Conclusions}

ACE2 has important counter-regulatory effects on the reninangiotensin system and has been implicated in COVID-19 pathogenesis. Medications that act on the renin-angiotensin system, including ACE inhibitors and Ang II receptor blockers, may impact COVID-19 infection and severity via potential interactions with ACE2; however, the direction and magnitude of these effects are unknown at this time. Several international societies have released statements discouraging discontinuation of ACE inhibitors and Ang II receptor blockers in patients who are treated with these medications for hypertension, heart failure, and chronic kidney disease amidst the COVID-19 pandemic [6॰]. Given the clear benefits of these agents in hypertension, chronic kidney disease, coronary heart disease, and diabetes, there is an urgent need for further research to improve our understanding of the relationship between agents that act on the renin-angiotensin system and outcomes among individuals with COVID-19, with several studies currently underway [6•].

Funding Information JBC is supported by K23-HL133843 from the National Heart, Lung, and Blood Institute. TCH is supported by T32HL007891 from the National Heart, Lung, and Blood Institute. AMS is supported by R01-HL146818 from the National Heart, Lung, and Blood Institute; UC4DK108173 from the National Institute of Diabetes and Digestive and Kidney Diseases; and a Loan Repayment Program Award from the National Heart, Lung, and Blood Institute. APB is supported by 1K01HL133468 from the National Heart, Lung, and Blood Institute.

\section{Compliance with Ethical Standards}

Conflict of Interest The authors declare no conflicts of interest relevant to this manuscript.

Human and Animal Rights and Informed Consent This article does not contain any studies with human or animal subjects performed by any of the authors.

\section{References}

Papers of particular interest, published recently, have been highlighted as:

- Of importance

1. Wu Z, McGoogan JM. Characteristics of and important lessons from the coronavirus disease 2019 (COVID-19) outbreak in 
China: summary of a report of 72314 cases from the Chinese Center for Disease Control and Prevention. JAMA. 2020.

2. Guan WJ, Ni ZY, Hu Y, Liang WH, Ou CQ, He JX, et al. Clinical characteristics of coronavirus disease 2019 in China. N Engl J Med. 2020.

3. Wang D, Hu B, Hu C, Zhu F, Liu X, Zhang J, et al. Clinical characteristics of 138 hospitalized patients with 2019 novel coronavirus-infected pneumonia in Wuhan, China. JAMA 2020.

4. Wu C, Chen X, Cai Y, Xia J, Zhou X, Xu S, et al. Risk factors associated with acute respiratory distress syndrome and death in patients with coronavirus disease 2019 pneumonia in Wuhan, China. JAMA Intern Med. 2020.

5. Sparks MA, South A, Welling P, Luther JM, Cohen J, Byrd JB, et al. Sound science before quick judgement regarding RAS blockade in COVID-19. Clin J Am Soc Nephrol. 2020.

6. Sparks MA, Hiremath S, South A, Welling P, Luther JM, Cohen JB, et al. "The coronavirus conundrum: ACE2 and hypertension edition" NephJC http://www.nephjc.com/news/covidace2. Accessed 13 Apr 2020. 2020. This is a multidiscplinary free open access medical education document by several physician scientists whose research focuses on the renin-angiotensin system, which provides a comprehensive overview of research related to ACE2 and COVID-19, including live updates as new research emerges. The site had $>\mathbf{2 6 0 , 0 0 0}$ page views within its first three weeks of launching.

7. South AM, Shaltout HA, Washburn LK, Hendricks AS, Diz DI, Chappell MC. Fetal programming and the angiotensin-(1-7) axis: a review of the experimental and clinical data. Clin Sci (Lond). 2019;133(1):55-74.

8. Soler MJ, Wysocki J, Batlle D. ACE2 alterations in kidney disease. Nephrol Dial Transplant. 2013;28(11):2687-97.

9. Guy JL, Jackson RM, Acharya KR, Sturrock ED, Hooper NM, Turner AJ. Angiotensin-converting enzyme-2 (ACE2): comparative modeling of the active site, specificity requirements, and chloride dependence. Biochemistry. 2003;42(45):13185-92.

10. Donoghue M, Hsieh F, Baronas E, Godbout K, Gosselin M, Stagliano N, et al. A novel angiotensin-converting enzyme-related carboxypeptidase (ACE2) converts angiotensin I to angiotensin 19. Circ Res. 2000;87(5):E1-9.

11. Sparks MA, Crowley SD, Gurley SB, Mirotsou M, Coffman TM. Classical renin-angiotensin system in kidney physiology. Compr Physiol. 2014;4(3):1201-28.

12. Vaughan DE. Angiotensin and vascular fibrinolytic balance. Am J Hypertens. 2002;15(1 Pt 2):3S-8S.

13. Gromotowicz-Poplawska A, Stankiewicz A, Kramkowski K, Gradzka A, Wojewodzka-Zelezniakowicz M, Dzieciol J, et al. The acute prothrombotic effect of aldosterone in rats is partially mediated via angiotensin II receptor type 1 . Thromb Res. 2016;138:114-20.

14. Lelis DF, Freitas DF, Machado AS, Crespo TS, Santos SHS. Angiotensin-(1-7), adipokines and inflammation. Metabolism. 2019;95:36-45.

15. Patel VB, Zhong JC, Grant MB, Oudit GY. Role of the ACE2/ angiotensin 1-7 axis of the renin-angiotensin system in heart failure. Circ Res. 2016;118(8):1313-26.

16. Flores-Munoz M, Work LM, Douglas K, Denby L, Dominiczak AF, Graham D, et al. Angiotensin-(1-9) attenuates cardiac fibrosis in the stroke-prone spontaneously hypertensive rat via the angiotensin type 2 receptor. Hypertension. 2012;59(2):300-7.

17. Wakahara S, Konoshita T, Mizuno S, Motomura M, Aoyama C, Makino Y, et al. Synergistic expression of angiotensin-converting enzyme (ACE) and ACE2 in human renal tissue and confounding effects of hypertension on the ACE to ACE2 ratio. Endocrinology. 2007;148(5):2453-7.

18. Soler MJ, Wysocki J, Ye M, Lloveras J, Kanwar Y, Batlle D. ACE2 inhibition worsens glomerular injury in association with increased
ACE expression in streptozotocin-induced diabetic mice. Kidney Int. 2007;72(5):614-23.

19. Wong DW, Oudit GY, Reich H, Kassiri Z, Zhou J, Liu QC, et al. Loss of angiotensin-converting enzyme-2 (Ace2) accelerates diabetic kidney injury. Am J Pathol. 2007;171(2):438-51.

20. Rice GI, Jones AL, Grant PJ, Carter AM, Turner AJ, Hooper NM. Circulating activities of angiotensin-converting enzyme, its homo$\log$, angiotensin-converting enzyme 2 , and neprilysin in a family study. Hypertension. 2006;48(5):914-20.

21. Imai Y, Kuba K, Rao S, Huan Y, Guo F, Guan B, et al. Angiotensinconverting enzyme 2 protects from severe acute lung failure. Nature. 2005;436(7047):112-6.

22. Oudit GY, Liu GC, Zhong J, Basu R, Chow FL, Zhou J, et al. Human recombinant ACE2 reduces the progression of diabetic nephropathy. Diabetes. 2010;59(2):529-38.

23. Wysocki J, Ye M, Rodriguez E, Gonzalez-Pacheco FR, Barrios C, Evora K, et al. Targeting the degradation of angiotensin II with recombinant angiotensin-converting enzyme 2 : prevention of angiotensin II-dependent hypertension. Hypertension. 2010;55(1): $90-8$.

24. Zhong J, Basu R, Guo D, Chow FL, Byrns S, Schuster M, et al. Angiotensin-converting enzyme 2 suppresses pathological hypertrophy, myocardial fibrosis, and cardiac dysfunction. Circulation. 2010;122(7):717-28 18 p following 28.

25. Gu H, Xie Z, Li T, Zhang S, Lai C, Zhu P, et al. Angiotensinconverting enzyme 2 inhibits lung injury induced by respiratory syncytial virus. Sci Rep. 2016;6:19840.

26. Ferrario CM, Jessup J, Chappell MC, Averill DB, Brosnihan KB, Tallant EA, et al. Effect of angiotensin-converting enzyme inhibition and angiotensin II receptor blockers on cardiac angiotensinconverting enzyme 2. Circulation. 2005;111(20):2605-10.

27. Ocaranza MP, Godoy I, Jalil JE, Varas M, Collantes P, Pinto M, et al. Enalapril attenuates downregulation of angiotensin-converting enzyme 2 in the late phase of ventricular dysfunction in myocardial infarcted rat. Hypertension. 2006;48(4):572-8.

28. Ishiyama Y, Gallagher PE, Averill DB, Tallant EA, Brosnihan KB, Ferrario CM. Upregulation of angiotensin-converting enzyme 2 after myocardial infarction by blockade of angiotensin II receptors. Hypertension. 2004:43(5):970-6.

29. Soler MJ, Ye M, Wysocki J, William J, Lloveras J, Batlle D. Localization of ACE2 in the renal vasculature: amplification by angiotensin II type 1 receptor blockade using telmisartan. Am J Physiol Ren Physiol. 2009;296(2):F398-405.

30. Walters TE, Kalman JM, Patel SK, Mearns M, Velkoska E, Burrell LM. Angiotensin converting enzyme 2 activity and human atrial fibrillation: increased plasma angiotensin converting enzyme 2 activity is associated with atrial fibrillation and more advanced left atrial structural remodelling. Europace. 2017;19(8):1280-7.

31. Ramchand J, Patel SK, Srivastava PM, Farouque O, Burrell LM. Elevated plasma angiotensin converting enzyme 2 activity is an independent predictor of major adverse cardiac events in patients with obstructive coronary artery disease. PLoS One. 2018;13(6): e0198144. This prospective observational study of $\mathbf{7 9}$ patients with obstructive coronary artery disease demonstrated that elevated ACE2 activity was independently associated with major adverse cardiovascular events over a median follow up of $\mathbf{1 0 . 5}$ years. The authors also observed that the frequency of elevated ACE2 activity was similar across users and non-users of ACE inhibitors and Ang II receptor blockers.

32. Roth M. Are patients with hypertension and diabetes mellitus at increased risk for COVID-19 infection? Lancet. 2020;8:e21.

33. South AM, Diz DI, Chappell MC. COVID-19, ACE2, and the cardiovascular consequences. Am J Physiol Heart Circ Physiol. 2020;318(5):H1084-H90.

34. Brown NJ, Vaughan DE. Prothrombotic effects of angiotensin. Adv Intern Med. 2000;45:419-29. 
35. Senchenkova EY, Russell J, Yildirim A, Granger DN, Gavins FNE. Novel role of T cells and IL-6 (interleukin-6) in angiotensin IIinduced microvascular dysfunction. Hypertension. 2019;73(4): 829-38. Using several mouse models, this study demonstrated that $T$ cell IL-6 mediates the thrombotic abnormalities found in hypertension via the ACE/Ang II pathway. Additionally, using human samples, the authors found that IL-6 promotes platelet aggregation, leading to increased risk of thrombosis.

36. Madjid M, Safavi-Naeini P, Solomon SD, Vardeny O. Potential effects of coronaviruses on the cardiovascular system: a review. JAMA Cardiol. 2020.

37. Mehta PK, Griendling KK. Angiotensin II cell signaling: physiological and pathological effects in the cardiovascular system. Am J Phys Cell Phys. 2007;292(1):C82-97.
38. Kuba K, Imai Y, Rao S, Gao H, Guo F, Guan B, et al. A crucial role of angiotensin converting enzyme 2 (ACE2) in SARS coronavirusinduced lung injury. Nat Med. 2005;11(8):875-9.

39. Deshotels MR, Xia H, Sriramula S, Lazartigues E, Filipeanu CM. Angiotensin II mediates angiotensin converting enzyme type 2 internalization and degradation through an angiotensin II type I receptor-dependent mechanism. Hypertension. 2014;64(6):136875 .

Publisher's Note Springer Nature remains neutral with regard to jurisdictional claims in published maps and institutional affiliations. 